\title{
O EU DOÉTICO E A FUSÃO dos opostos em Jorge de Lima
}

\section{Roberval Dereyr}

O problema da cisão entre instâncias opostas está na base da própria natureza do homem, enquanto animal simbólico - o ser da linguagem por excelência. A propósito, fazemos nossas as palavras de Octavio Paz, que diz: "O homem é homem graças à linguagem, graças à metáfora original que o fez ser outro e o separou do mundo natural. (...) é um ser que se criou ao criar uma linguagem. Pela palavra, o homem é uma metáfora de si mesmo". ${ }^{1}$

Por essa cisão básica surgem todas as dicotomias que o caracterizam. Neste trabalho, tentaremos trazer à tona alguns pontos referentes a esta questão no contexto da obra poética de Jorge de Lima. Ou seja, tomaremos alguns aspectos, na tentativa de apontar pistas percorridas pelo artista, conscientemente ou não, no sentido de conciliar, aos níveis temático e estrutural, a questão dos opostos no curso da sua obra.

E talvez seja oportuno começarmos por uma constatação: trata-se de um poeta ocidental, marcado pela influência do cristianismo, cuja fundamentação encontra ligações diretas com a própria base da filosofia no ocidente. Veremos, ao longo dessa discussão, que se trata de um fato relevante no processo de formação da obra de Jorge de Lima. No nosso entender existe um impasse constitutivo na obra deste poeta, 
superado apenas, e após muitas quedas, em sua grande obra da maturidade $-A$ invenção de Orfeu. Trata-se justamente da presença marcante de uma visão cristã, pela qual se estabelecem dicotomias cujos pólos delimitam-se de forma muito rígida: céu/inferno, bem/mal, salvação/perdição, corpo/alma.

Tais dicotomias, como dissemos, encontram fundamento na própria formulação básica da filosofia ocidental: estamos nos referindo ao princípio da identidade, do pré-socrático Parmênides, assim expresso: “O ser é, o não-ser não é.” Aqui, o ser seria sinônimo do imutável, do eterno, do essencial, enquanto o não-ser corresponderia ao transitório, ao circunstancial, a tudo que, enfim, representasse o mundo da realidade aparente. É com base neste princípio que surge, por exemplo, o mundo das idéias de Platão, segundo o qual cada coisa existente não passa de sombra, mera projeção imperfeita do seu ser verdadeiro: a idéia imutável e perfeita a ela correspondente. Já aqui podemos sentir mais de perto a influência do pensamento grego clássico sobre o Cristianismo, com sua concepção do corpo como algo distinto e até mesmo inimigo da alma - o que justifica as noções marcantes da culpa e do pecado entre os cristãos.

Cheguemos, pois, ao impasse. Formado sob profunda influência cristã, com suas cisões bastante realçadas, Jorge de Lima é também, e sobretudo, um poeta. Ou seja: é o criador de uma linguagem que, por natureza, contraria de frente as rígidas divisões formuladas por Parmênides, por Platão (que, não é de se estranhar, expulsa da sua República os poetas) e pelo Cristianismo. Pois na linguagem poética - em seu sentido básico - os contrários se tocam e, não raro, se fundem e se confundem. Por isso, a sua manifestação representa simbolicamente uma volta às origens da própria linguagem - momento em que sujeito e objeto, consciente e inconsciente, individual e coletivo, essencial e aparente apresentam-se como algo único e indissociável.

Esta contradição foi, certamente, uma das tensões básicas a serem ajustadas no processo de formação da obra do poeta alagoano. O que o coloca numa situação sob certo aspecto singular: a de ser um poeta moderno para quem, contraditoriamente, e muito tempo depois de Nietzsche, Deus não está morto: um poeta que oscila entre a modernidade dessacralizada e fragmentária e os períodos antecedentes, marcados pelo logocentrismo, situando-se neste o cristianismo. Somos inclusive da opinião de que, senão exclusivamente, mas também por isso, o poeta necessitou trazer para o bojo da sua obra uma carga imensa de valores e elementos (cristãos, afros, pagãos, da própria tradição literária, da cultura brasileira etc.), como forma de superar, por meio de um ambicioso projeto, as limitações cristãs e logocêntricas, e conquistar uma autonomia para sua produção poética, em seus diversos níveis de realização. 
Poderíamos agora, já com o intuito de verificar alguns dos argumentos anteriormente colocados, afirmar ser a poesia de Jorge de Lima, em sua fase inicial, fortemente marcada pela visão parmenídica do que é verdadeiro e do que é falso. Em Sonetos, seu primeiro livro, encontramos poemas cujos títulos são reveladores. Exemplo: o soneto "A verdade" ${ }^{2}$, onde podemos verificar: primeiro, uma tendência à utilização da linguagem como instrumento para veiculação de uma mensagem - a idéia da existência de uma certa verdade; segundo, "a verdade" concebida no poema é "alcançada", por assim dizer, por um método comparativo bem delineado: o poeta toma um elemento da natureza (uma planta), argumenta em torno dele, associando-o, num segundo momento, à idéia da Verdade, com inicial maiúscula. Do mesmo modo, tudo que se opõe ao natural, tudo que se situa no mundo da cultura é tomado como o contrário da verdade.

Como vimos, tanto no nível da idéia quanto da estrutura, o poema em questão configura-se numa linguagem que passa a girar em torno de um objeto determinado, dando inclusive a impressão de não ser, também, ela mesma o seu objeto. Sob este aspecto, observamos um certo grau de subordinação ao princípio lógico, que ainda se impõe como elemento central articulador. E assim, de forma conclusiva e precisa, o poeta constrói o último verso: "Esta planta - a verdade; a treva - o preconceito".

E apenas para citarmos outros poemas cujos títulos dizem por si sós, indicamos, além de "A verdade", "Mentira" 3 (cujo último verso reforça a idéia do pecado original: "É pecado viver e o mundo inteiro peca") e "O pensamento" ${ }^{4}$ (mais uma vez o discurso da mensagem, o logocentrismo: o pensamento, comparado a Deus, é concebido como algo fundamental, que vence o tempo e a própria morte).

Em relação aos XIX alexandrinos, podemos tecer basicamente as mesmas considerações que aos Sonetos. Uma grande mudança, porém, verificamos no livro seguinte, intitulado Poemas. Aí ocorre, de fato, uma ruptura: desaparecem, juntamente com as formas fixas e os temas tradicionais, certas marcas muito rígidas da cisão entre os opostos. Já no primeiro poema, fazendo uso do verso livre, e não mais de forma tão categórica e direta, o poeta assume a figura do menino que rompe com o seu passado - no caso, toda uma tradição européia. Em lugar disto, assume uma postura nova, informal, brasileira. Ao mesmo tempo, expressa uma outra visão da ficção e da própria poesia ${ }^{5}$ :

Faz de conta que os sabugos são bois... 
Faz de conta...

Faz de conta...

E os sabugos de milho

Mugem como bois de verdade...

Percebemos aqui, de forma simples, os primeiros sinais de fusão do real com o irreal, pela linguagem poética, ou, como diz ele próprio, “com o mundo maravilhoso/ que ele tirou do nada".

Em Novos poemas ele publica o poema "Meus olhos", onde surge a questão do eu e do outro, simbolizada nos olhos pretos do poeta e nos olhos verdes de Nossa Senhora ${ }^{6}$. A propósito, o tema do olhar, reincidente na obra do poeta, constitui-se, ao nosso ver, num dos pontos de articulação e (re)conciliação entre os opostos, a exemplo do binômio essência x aparência, inclusive porque os olhos são, efetivamente, os órgãos da percepção que melhor expressam - no sentido de tornar presente - o interior e o exterior do ser humano. Além disso, são eles que melhor possibilitam uma percepção simultânea e não linear da realidade circundante. O que equivale a dizer: influenciam de forma decisiva no processo de formação e de manifestação da imagem poética.

Já em Poemas escolbidos - que segue basicamente a mesma linha dos dois livros anteriores -, o poeta volta a falar de Cristo, mas num tom bastante humorado e descontraído, como em "Cristo redentor do corcovado" 7 :
Adoro esse Cristo turista
de braços abertos
que procura equilíbrio
na montanha brasileira.

No texto seguinte - "Poema de natal" ${ }^{8}$-, Jorge de Lima trata Jesus como uma criança, e com bastante intimidade: trata-o como ser humano. Tal tratamento, que inclui a libertação dos dogmas e dos princípios rígidos do cristianismo institucionalizado, representa, muito provavelmente, um passo importante no sentido de, mais adiante, a partir de $A$ túnica inconsútil, mas sobretudo em $A$ invenção de Orfeu, operar-se uma grande fusão. ${ }^{9}$ Refiro-me à fusão entre elementos diversos - cristãos, indígenas, afros, pagãos... - numa linguagem autônoma, plurifacetada e açambarcadora, própria da grande poesia, sobretudo no contexto da modernidade. 
Todos esses argumentos convergem para o ponto de vista segundo o qual a questão dos opostos se altera e se resolve na obra de Jorge de Lima, à medida que este vai se tornando um poeta da modernidade, o que se observa por algumas rupturas básicas no plano da linguagem, e pela incorporação de novos elementos e novas concepções. Certo que o poeta não será mais um a querer matar Deus ou recrucificar Jesus Cristo. Mas, em vez disso, assumirá ele próprio o seu lugar. ${ }^{10}$ Isto quer finalmente dizer que Cristo (a verdade, a essência) e o homem (o circunstancial, a imagem) se fundem através da poesia.

Retomando Cristo em sua essencialidade (pelo processo de desdogmatização, seguido de uma ressacralização pela poesia), o poeta traz à tona algo desconcertante, algo "desviado" - mas desviado em relação ao que já não diz quase nada do cristianismo de Cristo. Sem desvio, portanto, é um desvio para a origem - eis por que ele assume simbolicamente o lugar de cristo em $A$ invenção de Orfeu. Confundido na figura do Filho, no dogma da Trindade, aparece a figura do poeta como criador. A essência de Cristo passa a ser mais um arquétipo configurativo do princípio e da natureza do ser poético.

A propósito, um outro aspecto pelo qual poderíamos chegar à questão dos opostos (e sua conciliação) na obra de Jorge de Lima diz respeito à forma como ele recorre e como trabalha certos arquétipos. Sabemos que a obra poética representa sempre a manifestação de uma linguagem arquetípica, enquanto expressão de uma experiência individual que é também coletiva. Uma linguagem que, evocando elementos particulares e acidentais, resulta sempre na manifestação da essencialidade do homem e do mundo. No caso específico de Jorge de Lima, percebemos a recorrência insistente e até sistemática a arquétipos como, por exemplo, o da figura feminina. Um exemplo marcante é, certamente, Mira-Celi - sobretudo no livro intitulado Encontro e anunciação de Mira-Celi. Aqui, a musa é simultaneamente anunciada como essência de Cristo (“Tu és cristocêntrica, Mira-Celi”) e da própria poesia: ${ }^{11}$

Tu és, ó Mira-Celi, a repercutida e o laitmotivo que aparece ao longo de meu poema.

$\mathrm{Ou}$

Às vezes, quando dobras uma página, perguntas:

- "Sou eu?" 
Mas, olhando depois a paisagem mudar tanto, no espaço de um segundo, encontras os teus membros na nudez de uma frase...

Uma outra evidência de que Mira-Celi representaria a manifestação da própria poesia - linguagem articulada para além dos parâmetros da causalidade - está expressa no mesmo poema acima citado:

Ora pareces marcha nupcial; és, no entanto, elegia.

Ora és sacerdotisa, musa, louca, pastora ou apenas ave.

Dei-te diversos nomes, para que ninguém te acompanhe.

E, ao final, a referência ao "imenso e misterioso poema sempre por terminar".

Tomando como referência este último verso, poderíamos associar naturalmente aos arquétipos que neste poema aparecem entrelaçados - Mira-Celi, Cristo e, no centro, a poesia -, o tema também arquetípico da viagem, na obra de Jorge de Lima. E com ele necessariamente vem à tona o problema do tempo e do espaço, cujas concepções, em $A$ invenção de Orfeu, por exemplo, alteram radicalmente o tratamento dado pelo poeta à questão dos opostos. Esclarecemos de antemão que a viagem, neste contexto, aparece ainda como sinônimo do processo de formação da obra, conforme veremos logo em seguida.

Se observarmos os diversos livros que compõem a obra poética de Jorge de Lima, pelo menos na ordem que nos é colocada em sua Poesia Completa (Nova Fronteira, $2^{\mathrm{a}}$ ed., 1980), perceberemos que ela se desenvolve num processo de idas e voltas. Trata-se de um movimento em círculos, em que novos elementos (conceptuais, formais e temáticos) são sempre incorporados, enquanto outros são retomados em perspectivas muitas vezes diversas das anteriores ${ }^{12}$. Verificamos, por exemplo, o uso alternado das formas fixas e do verso livre, a evocação sistemática de temas e motivos da cultura ocidental greco-romana, num momento, bem como da cultura negra e latino-americana, em outro, num processo gradativo e crescente (muitas vezes tempestuoso) de entrelaçamento e de superposição de elementos os mais diversos, no tempo e no espaço. Sob este aspecto, podemos aplicar integralmente a esta obra o ponto de vista de Roland Barthes, segundo o qual "a literatura faz girar os saberes" e, muito importante, "de forma indireta, sem fixá-los." "13 Seguramente, o poeta opera um processo de dessetorialização dos diversos elementos dos quais lança mão, rearticulandoos - como o fez Eliot - a partir de um novo centro de atração, o da obra. 
Símbolos, fatos e valores pertencentes a culturas diferentes, em tempos e espaços também diferentes, são associados e, mais ainda, apropriados como fragmentos que passam a adquirir renovados sentidos no contexto espácio-temporal do poema. Em $A$ invenção de Orfeu, exemplo mais adequado, cristianismo e paganismo convivem e, pela poesia, se confundem: Orfeu e Cristo são e não são os mesmos no vasto bojo do en poético.

Tudo isto representa uma visão radicalmente mais complexa e matizada que aquela com a qual nos defrontamos nos Sonetos, marcados pela visão maniqueísta do bem e do mal, do verdadeiro e do falso. A questão, por exemplo, da essência x aparência (e, por extensão, a dos opostos em geral), tal como é tratada em $A$ invenção de Orfeu, talvez encontre paralelo mais adequado, no campo da filosofia ocidental, entre os fenomenólogos, a exemplo de Gaston Bachelard e Martin Heidegger. Este, na Introdução à metafisisica, diz: "A essencialização da aparência está no aparecer." ${ }^{14}$ Se compararmos esta concepção de Heidegger ao princípio da identidade de Parmênides, verificaremos a existência entre ambos de uma distinção tão marcante quanto aquela existente entre a poesia inicial de Jorge de Lima e seu vasto invento da maturidade. Heidegger aqui recupera, se não no nível da estrutura da linguagem que produz, pelo menos no plano conceptual, a indissociabilidade entre a essência e a aparência, ao tomar estas categorias como meros aspectos, apenas racionalmente identificáveis, de um mesmo processo: o processo de presentificação do ser. No nosso caso, o processo de revelação poética.

A afirmação de Heidegger nos parece ainda de acordo com a de Bachelard quando este afirma textualmente que a relação de uma imagem poética nova com um "arquétipo adormecido no inconsciente, (...) não é propriamente causal." E mais: "Por sua novidade, por sua atividade, a imagem poética tem um ser próprio, um dinamismo próprio. Ela advém de uma ontologia direta." ${ }^{15}$ Em outras palavras: a imagem poética (ou o poema: conjunto articulado de imagens) prescinde simplesmente de uma coerência lógica, no sentido tradicional. Um poema simplesmente é , como algo que se acrescenta ao mundo, à realidade, e que se sustenta a si mesmo, à revelia de qualquer noção do falso e do verdadeiro, do lógico e do ilógico. A imagem poética é encantamento, magia, revelação. A propósito, com estes argumentos poderíamos justificar o caráter hermético de muitas das passagens de $A$ invenção de Orfeu, onde versos e imagens surgem às vezes contrariando cabalmente a expectativa racional e culturalmente condicionada do leitor. Sabemos que a valorização, bem como as próprias noções de clareza e de coerência lógica são construções da cultura ocidental logocêntrica. 
O hermetismo em $A$ invenção de Orfeu não é, portanto, uma imperfeição, mas, ao contrário, a expressão de algo que, por natureza, é hermético. Muitas vezes ocorre de um verso, ou conjunto de versos, estarem sintaticamente estruturados mas, no plano da imagem, expressarem o normalmente inconcebível ou até ininteligível. Um exemplo: ${ }^{16}$

Enfim, tudo vazio, enorme ser, contendo-se divino no seu ritmo, voraz ritmo implacável, inconsciente, no gesto em que fiquei tocando as coisas, e as coisas desafazendo-se em mim próprio.

Outro exemplo: ${ }^{17}$

Andamos como uma só, só solitude, só uma estrada andando sobre nós, existimos poetas antes de nascermos.

A imagem final da primeira citação aponta para um estado em que desaparece a noção de sujeito como algo separado de seu objeto. Assim, não é de causar espanto que esta imagem (como as da segunda citação, onde sujeito e objeto invertem os papéis, e o depois antecede o antes) provoque de imediato um estranhamento radical ao espírito analítico, que opera sempre por raciocínios lógicos e no sentido de seccionar seu objeto de estudo, bem como a própria linguagem de que se utiliza para fazê-lo.

Falávamos anteriormente que a formação da obra poética de Jorge de Lima dáse por um processo de idas e vindas. Tais movimentos circulares desembocam finalmente em $A$ invenção de Orfeu, onde, conjugados todos os círculos, forma-se uma esfera. Ou melhor: uma ilha, ou mesmo um planeta, com solo, subsolo, supersolo, como a simbolizar a própria manifestação poética enquanto linguagem dotada de estratos, camadas - uma linguagem arqueológica. Exemplo completo a este respeito podemos encontrar já no Canto I - Fundação da ilha -, onde o poeta, por assim dizer, expõe todos os símbolos, valores e instâncias a serem articulados ao longo de seu vasto poema.

Por fim, podemos dizer que Jorge de Lima situa-se na mesma linha de poetas como T. S. Eliot, para quem a tradição representa uma grande carga - verdadeira via crucis a ser superada. Para fazer girar e produzir tão densa e tão variada massa de 
saberes, impôs-se o poeta a engenhosa tarefa de erguer uma máquina - $A$ invenção de Orfeu -, cujo funcionamento muitas vezes beira a monotonia e a lentidão. Enorme o vocabulário, vasta a gama de símbolos, instâncias, formas e temas mobilizados. Mas, finalmente, seu espírito barroco latino-americano alia-se a toda uma tradição das culturas ocidental, indígena e afro-brasileira, operando a aproximação de vários e heterogêneos elementos, no espaço e no tempo do universo poético.

Desta forma, a visão dos opostos enquanto pólos estanques e mutuamente exclusivos cede lugar à noção de processo; os pontos de chegada são igualmente pontos de partida, as retas culminam em círculos, nesta obra - $A$ invenção de Orfeu - que se projeta vertical e horizontalmente e que poderia ser comparada a uma esfera em ebulição.

\section{$\operatorname{son}$}

\section{NOTAS}

1 PAZ, Octavio. O arco e a lira, 1982, p. 42.

2 LIMA, Jorge de. Poesia completa, 1980, vol. 1, p. 45.

3 Idem, p. 46.

4 Idem, p. 50.

5 Idem, p. 74.

6 LIMA, Jorge de. Poesia completa, 1980, p. 135.

7 Idem, p. 147.

8 Idem, p. 147-8.

9 Antes de $A$ invenção de Orfeu, em Tempo e eternidade, o poeta volta ao cristianismo com suas cisões básicas. Aí, deus reaparece como "essência", em contraposição ao mundo, que é aparência. Em Quero ser ensinado por Deus (p. 199), temos: "Ciência não me satisfaz./Mundo não me satisfaz./Diabo não me distrai." Ou: "Os apoios terrestres são frágeis./As montanhas são fracas demais". E, no final do poema, o apelo dramático à cirurgia: "Deus me degole do mundo." Já em A túnica inconsútil (título, aliás, revelador), volta a flexibilizar. No Poema em Cristo (p. 219), lemos: "tenho os movimentos alargados./Sou ubíquo: estou em Deus e na matéria." Ainda no mesmo poema: "estou molhado nos limos primitivos,/e ao mesmo tempo ressôo as trombetas finais,/compreendo todas as línguas, todos os gostos, todos os signos,/tenho glóbulos do sangue das raças mais opostas". Como vemos, à quebra de cisão corresponde, por um lado, a reconciliação dos contrários e, por outro, o alargamento e a esfericização do eu poético. 
10 Poesia completa, vol. 2, p. 273-4.

11 Idem, vol.1, p. 287 (1a citação), p. 284 ( $2^{\mathrm{a}}$ citação) e p. 285 (3 citação).

12 Tomemos, por exemplo, o Canto VIII - Biografia - vasto e denso poema, que é a biografia do eu poético. Dele poderíamos citar várias passagens em que o próprio poeta, de alguma forma, abaliza nossos argumentos. Fiquemos apenas com estas: "Neste poema informe e sem balizas/recria-se uma ilha repetida/com seu tomo de pedra adormecido." Ou: "Ilha de infâncias idas, hoje achada,/virada para todos os quadrantes, /mas inconsútil corpo religado/pelo umbigo celeste às Três Pessoas,/presentes na precária geografia.” (p. 199)

13 Barthes, 1980 , p. 18.

14 Heidegger, 1978, p. 127.

15 Bachelard, 1974, p. 341.

16 Op. Cit., p. 255.

17 Bachelard, p. 198. Ou ainda (p. 268): "Eu depois de amanhã ressuicidei/o cilindro que envolve o sem que eu vibro,/apaguei as pupilas dos meus dedos."

PEREYR, Roberval. O eu poético e a fusão dos opostos em

Roberval Alves Pereira é Professor Adjunto da Universidade Estadual de Feira de Santana. Graduado em Letras pela UEFS, Mestrado em Letras pela UFBA, Doutor em Letras pela UNICAMP. Publicou: As roupas do Nu, 1981; Ocidentais, 1987; Concerto de ilhas, 1997; Saguão de Mitos, 1998; Amálgama, 2000; A Unidade Primordial da Lirica Moderna, 2000. É Diretor das revistas de poesia Hera e Olho D'Água; e Coordenador do Núcleo de Criação Literária da UEFS. 